\title{
Bioinformatics analyses and biological function of IncRNA ZFPM2-AS1 and ZFPM2 gene in hepatocellular carcinoma
}

\author{
YI LUO $^{1 *}$, XIAOJUN WANG ${ }^{2 *}$, LING MA $^{3 *}$, ZHIHUA MA $^{4}$, SHEN LI $^{5}$, XIAOYU FANG $^{6}$ and XIANGYU MA ${ }^{1}$ \\ ${ }^{1}$ Department of Epidemiology, College of Preventive Medicine, Army Military Medical University; \\ ${ }^{2}$ Department of Hepatobiliary Surgery, The First Affiliated Hospital of Army Military Medical University, \\ Chongqing 400038; ${ }^{3}$ Department of Pediatrics, Banan People's Hospital of Chongqing, Chongqing 401320; \\ ${ }^{4}$ Department of Anesthesia, The First Affiliated Hospital of Army Military Medical University, \\ Chongqing 400038; ${ }^{5}$ The Second Clinical College, Chongqing Medical University, Chongqing 400010; \\ ${ }^{6}$ College of Preventive Medicine, Southwest Medical University, Luzhou, Sichuan 646000, P.R. China
}

Received August 6, 2019; Accepted November 14, 2020

DOI: 10.3892/ol.2020.11485

\begin{abstract}
Hepatocellular carcinoma (HCC) remains one of the most lethal malignant tumors worldwide; however, the etiology of HCC still remains poorly understood. In the present study, cancer-omics databases, including The Cancer Genome Atlas, GTEx and Gene Expression Omnibus, were systematically analyzed in order to investigate the role of the long non-coding RNA (lncRNA) zinc finger protein, FOG family member 2-antisense 1 (ZFPM2-AS1) and the zinc finger protein, FOG family member 2 (ZFPM2) gene in the occurrence and progression of HCC. It was identified that the expression levels of lncRNA ZFPM2-AS1 were significantly increased in HCC tissues, whereas expression levels of the ZFPM2 gene were significantly decreased in HCC tissues compared with normal liver tissues. Higher expression levels of ZFPM2-AS1 were significantly associated with a less favorable prognosis of HCC, whereas higher expression levels of the ZFPM2 gene were associated with a more favorable prognosis of HCC. Genetic alterations in the ZFPM2 gene may contribute to a worse prognosis of HCC. Validation of the GSE14520 dataset also demon stared that ZFPM2 gene expression levels were significantly decreased in HCC tissues $(\mathrm{P}<0.001)$. The receiver operating characteristic (ROC) analysis of the ZFPM2 gene indicated high accuracy of this gene in distinguishing between $\mathrm{HCC}$ tissues and non-tumor tissues. The areas under the ROC curves were $>0.8$. Using integrated strategies, the present study
\end{abstract}

Correspondence to: Professor Xiangyu Ma, Department of Epidemiology, College of Preventive Medicine, Army Military Medical University, 30 Gaotanyan Street, Shapingba, Chongqing 400038, P.R. China

E-mail:xymacq@hotmail.com

${ }^{*}$ Contributed equally

Key words: hepatocellular carcinoma, ZFPM2-AS1, ZFPM2, bioinformatics analysis, prognosis demonstrated that lncRNA ZFPM2-AS1 and the ZFPM2 gene may contribute to the occurrence and prognosis of HCC. These findings may provide a novel understanding of the molecular mechanisms underlying the occurrence and prognosis of HCC.

\section{Introduction}

Hepatocellular carcinoma (HCC) is one of the most lethal malignant tumors worldwide, with an incidence rate of $40.0 \%$ in men and $15.3 \%$ in women per 100,000 population in China $(1,2)$. According to the Global Burden of Disease Study 2017, 820,000 individuals succumbed to HCC worldwide (3). Among them, the number of HCC-associated mortalities in China $(\sim 422,000)$ accounted for $51.5 \%$ of global HCC-associated mortalities (4).

Long non-coding RNAs (lncRNAs) are a class of non-coding RNAs $>200$ nucleotides in length (5). Previous studies have shown that lncRNAs serve a regulatory role in tumor development and prognosis and can be potential tumor biomarkers and therapeutic targets (6,7). Meanwhile, lncRNAs have been found to serve a role in chromatin modification, transcription and post-transcriptional processing in HCC (8-11). Notably, overexpression of IncRNA HOTAIR, which was previously reported in breast cancer, was first identified to predict tumor recurrence in patients with HCC following liver transplantation $(12,13)$. Subsequent studies have reported that IncRNAs: MALAT1, HULC, GAS5, NEAT1, PCNA-AS1, PVT1, TUG1 and HOTTIP are associated with the development of HCC (11,14-17). IncRNA zinc finger protein, FOG family member 2-antisense 1 (ZFPM2-AS1), located on the 8q23 chromosome and next to the zinc finger protein, FOG family member 2 (ZFPM2) gene, serves a role in carcinogenesis and tumor progression in HCC and gastric cancer $(18,19)$. The ZFPM2 gene modulates the activity of GATA family proteins and serves a role in heart morphogenesis and development of coronary vessels $(20,21)$. Previous studies also revealed that ZFPM2 could cooperate with GATA factors and contribute to the occurrence of ovarian tumors, neuroblastoma, testicular carcinoma, germ cell tumors, Wilms' 
tumor, gliomas, glioblastoma, lung cancer, breast cancer and osteosarcoma (22-31). The chromosome $8 \mathrm{q} 23$ region is a high susceptibility locus for several types of cancer and genome-wide association studies (GWAS) have identified a number of cancer-associated single nucleotide polymorphisms that are adjacent to the ZFPM2-AS1 and ZFPM2 gene in this region (32-37).

Considering the promising role of the lncRNA ZFPM2-AS1 and the ZFPM2 gene in carcinogenesis and prognosis of several types of cancer, it was hypothesized that IncRNA ZFPM2-AS1 and the ZFPM2 gene also contribute to the development and prognosis of HCC. In present study, a series of bioinformatic and clinical analyses were performed to investigate the potential functions of lncRNA ZFPM2-AS1 and the ZFPM2 gene in the process of carcinogenesis and progression of HCC.

\section{Materials and methods}

Expression of ZFPM2-AS1 and ZFPM2 gene in the cancer genome atlas (TCGA) and GTEx tissues. The comparison of the expression levels of ZFPM2-AS1 and ZFPM2 genes in HCC and non-tumor tissues was performed using GEPIA version 2.0 (37), during which TCGA (https://portal.gdc.cancer. gov) HCC samples were compared with GETx (https://www. gtexportal.org/home) samples, which were used as controls. The associations of expression levels of ZFPM2-AS1 and the ZFPM2 gene with the prognosis of HCC and other digestive system tumors were evaluated using the Kaplan Meier plotter (http://kmplot.com/analysis), which presents overall survival, disease free survival, relapse free and progression free survival (38), and GEPIA.

Validation of expression of ZFPM2-AS1 and ZFPM2 gene in clinical tissues. The present study was approved by the Ethics Committee of the Army Military Medical University (Chongqing, China) and written informed consent was provided by all participants prior to the study start. A total of $53 \mathrm{HCC}$ and paired adjacent normal tissues $(>2 \mathrm{~cm}$ from tumor tissues) 45 men and 8 women; age range, 30-74 years; median age, 53 years) were collected from the Department of Hepatobiliary Surgery (Chongqing, China) between November 2017 and May 2019, following surgical resection. All diagnoses were blindly confirmed by at least two pathologists at The First Affiliated Hospital of Army Military Medical University, and patients who received radiofrequency ablation, chemoradiotherapy or other treatments prior to surgery were excluded from the present study. Samples were subsequently stored at $-80^{\circ} \mathrm{C}$, prior to subsequent experimentation.

Reverse transcription-quantative ( $R T-q) P C R$. Total RNA was extracted from HCC tissues using TRIzol ${ }^{\circledR}$ reagent (Invitrogen; Thermo Fisher Scientific, Inc.). cDNA was synthesized using the PrimeScript RT reagent kit with gDNA Eraser (Takara Bio, Inc.), and qPCR was performed using TB Green Premix Ex Taq II (Takara Bio, Inc.). The following primer sequences were used for qPCR: ZFPM2-AS1 forward, 5'-GCTTCTATG CСТTCСТTCССТT-3', and reverse, 5'-CTCСАТАСТСТC CCTGGGTT-3'; ZFPM2 forward, 5'-GCTACCCTCCCG TCATTT-3', and reverse, 5'-TTAGCCATCTGCTGCCAT-3'; and $\beta$-actin forward, 5'-CCACGAAACTACCTTCAACTC C-3; and reverse, 5'-GTGATCTCCTTCTGCATCCTGT-3'. The following thermocycling conditions were used for qPCR: Initial denaturation at $95^{\circ} \mathrm{C}$ for $30 \mathrm{sec}$; 40 cycles of denaturation at $95^{\circ} \mathrm{C}$ for $5 \mathrm{sec}$, annealing and elongation at $60^{\circ} \mathrm{C}$ for $30 \mathrm{sec}$; and a final extension at $72^{\circ} \mathrm{C}$ for $30 \mathrm{sec}$. Relative ZFPM2-AS1 and ZFPM2 mRNA levels were measured using the $2^{-\Delta \Delta \mathrm{Cq}}$ method (39) and normalized to the internal reference gene $\beta$-actin.

Interaction network and functional enrichment analyses. To investigate the biological functions and pathways of ZFPM2-AS1 and the ZFPM2 gene, gene-gene and protein-protein interaction (PPI) network analysis of the ZFPM2 gene was conducted using the GeneMANIA (http://genemania.org) and Search Tool for the Retrieval of Interacting Genes/Proteins (STRING) database version 11.0 (40). Genes associated with ZFPM2 and ZFPM2-AS1 were initially identified using the COXPRESdb database (version 7.3; https://coxpresdb.jp). Subsequently, Kyoto Encyclopedia of Genes and Genomes (KEGG) pathway and Gene Ontology (GO) analyses of ZFPM2-AS1 and ZFPM2-associated genes were performed using Database for Annotation, Visualization and Integrated Discovery (DAVID) version 6.8 (david.ncifcrf.gov/home.jsp).

Determination of genetic mutation status of the ZFPM2-AS1 lncRNA and ZFPM2 gene. To investigate the underlying mechanisms relevant to mutation status of ZFPM2-AS1 and ZFPM2 gene, the cBioPortal database (cbioportal. org/) was utilized. Kaplan-Meier survival estimates for overall survival of HCC patients, with or without mutations of the ZFPM2 gene was also analyzed, using the log-rank test.

Validation of the GEO dataset. The validation of the expression levels of the ZFPM2 gene in HCC tissues and adjacent normal tissues was further conducted with the GEO dataset GSE14520 (41). The receiver operating curve (ROC) with the area under the curve (AUC) value for assessing the predictive accuracy and discriminative ability of ROC was drawn to identify the diagnostic significance of expression level of the ZFPM2 gene.

Statistical analysis. SPSS version 22.0 (IMB Corp.) and GraphPad Prism version 7.0 (GraphPad Software, Inc.) were used for statistical analyses. $\mathrm{P}<0.05$ was considered to indicate a statistically significant difference. All results are presented as mean \pm standard deviation (unless otherwise shown). One-way ANOVA tests were used to evaluate the differences in ZFPM2-AS1 and ZFPM2 expression in clinical stages of HCC, while Wilcoxon's test was used for paired continuous variables. The $\chi^{2}$ test was used to evaluate differences in categorical variables. All expression data were log transformed for differential analysis.

\section{Results}

Associations between expression levels of lncRNA ZFPM2-AS1 and the ZFPM2 gene with clinical significance 
Table I. Characteristics of patients with HCC from TCGA and GTEx datasets.

\begin{tabular}{|c|c|c|c|}
\hline Variables & HCC cases (TCGA), $n$ & Controls (GTEx), $\mathrm{n}$ & P-value \\
\hline Sex & & & 0.799 \\
\hline Male & 255 & 123 & \\
\hline Female & 122 & 56 & \\
\hline Age at diagnosis, years (mean \pm standard deviation) & $59.5 \pm 13.5$ & & \\
\hline \multicolumn{4}{|l|}{ Child-Pugh score } \\
\hline A & 223 & & \\
\hline $\mathrm{B}$ & 21 & & \\
\hline $\mathrm{C}$ & 1 & & \\
\hline Unknown & 132 & & \\
\hline Creatinine value, $\mathrm{mg} / \mathrm{dl}$ & $2.76 \pm 11.7$ & & \\
\hline \multicolumn{4}{|l|}{$\mathrm{HCC}$ risk factor } \\
\hline Alcoholism & 76 & & \\
\hline Hepatitis B infection & 98 & & \\
\hline Hepatitis C infection & 52 & & \\
\hline \multicolumn{4}{|l|}{ Family cancer history } \\
\hline Yes & 114 & & \\
\hline No & 212 & & \\
\hline \multicolumn{4}{|l|}{ Neoplasm histological grade } \\
\hline G1 & 55 & & \\
\hline G2 & 180 & & \\
\hline G3 & 124 & & \\
\hline G4 & 13 & & \\
\hline \multicolumn{4}{|l|}{ Metastasis } \\
\hline No & 272 & & \\
\hline Yes & 105 & & \\
\hline
\end{tabular}

The publicly available GTEX data only provided data on sex. HCC, hepatocellular carcinoma; TCGA, The Cancer Genome Atlas.

of $H C C$. First the associations between the expression levels of ZFPM2-AS1 and the ZFPM2 gene and the clinical characteristics of HCC in TCGA and GTEx samples were analyzed. Table I presents the clinical characteristics of the patients from TCGA and GTEx databases (only sex available for GTEx), including sex, age at diagnosis, Child-Pugh score (42), creatinine value, HCC risk factor, family cancer history (data for 326 samples available), neoplasm histological grade (43) (data for 372 samples available) and metastasis status. The expression levels of lncRNA ZFPM2-AS1 were higher in HCC tissues compared with normal liver tissues (Fig. 1A), whereas the expression levels of the ZFPM2 gene were significantly lower in HCC tissues compared with normal liver tissues (Fig. 1C). No significant difference between the clinical stages of HCC and ZFPM2-AS1 (Fig. 1B; P=0.136) and ZFPM2 (Fig. 1D; $\mathrm{P}=0.935$ ) expression levels were observed. For the survival of patients with HCC it was observed that higher expression levels of ZFPM2-AS1 were significantly associated with a less favorable prognosis (Fig. 2A), whereas higher expression levels of the ZFPM2 gene were significantly associated with better prognosis of HCC (Fig. 3). These bioinformatic results were also verified using clinical samples. The expression levels of lncRNA ZFPM2-AS1 were significantly higher in HCC tissues compared with adjacent normal tissues (Fig. 4B; $\mathrm{P}<0.001$ ), whereas the expression levels of the ZFPM2 gene were significantly lower in HCC tissues compared with adjacent normal tissues (Fig. 4A; $\mathrm{P}<0.001$ ).

Gene-gene and PPI network of the lncRNA ZFPM2-AS1 and ZFPM2 gene. According to the results obtained from COXPRESdb, IncRNA ZFPM2-AS1 was associated with the ZFPM2 gene. Thus, gene-gene and PPI network analysis of the ZFPM2 gene were conducted using the GeneMANIA and STRING tools and it was demonstrated that ZFPM2 primarily associated with GATA factors, including GATA1, GATA3 and GATA4 (Figs. 5 and 6).

Clinical significance of genetic alterations of the lncRNA ZFPM2-AS1 and ZFPM2 gene. Using the cBioPortal database, $9 \%(93 / 1,052)$ of samples were identified as harboring a mutated ZFPM2 gene. From Kaplan-Meier survival analysis, the overall survival rate demonstrated statistical differences, which means patients with HCC with ZFPM2 mutations had a less favorable prognosis compared with those without ZFPM2 mutations ( $\mathrm{P}=0.0331$; Fig. 7). 
A

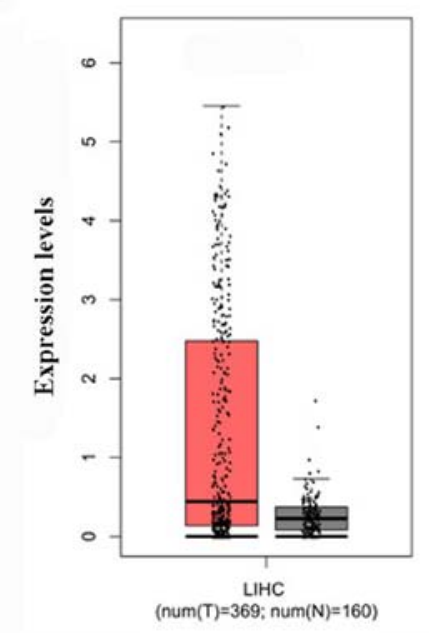

ZFPM2

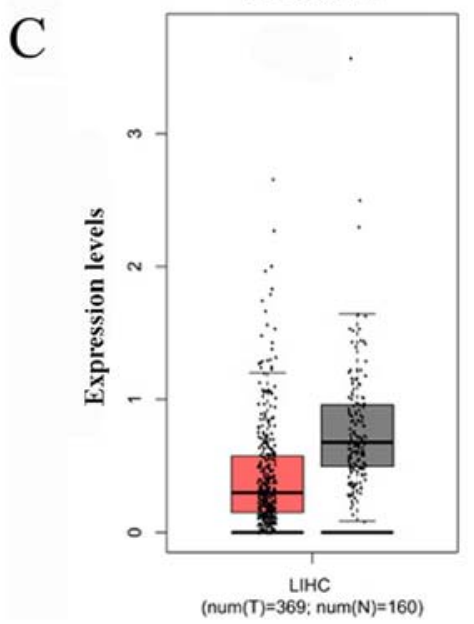

B

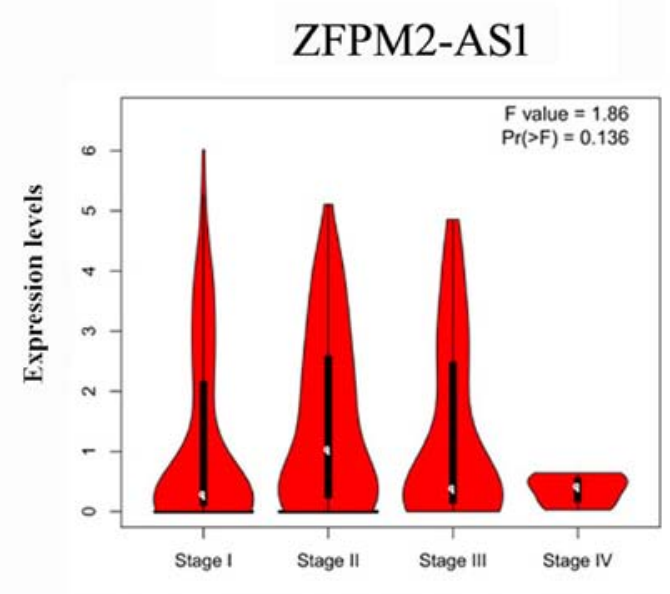

$\mathrm{D}$

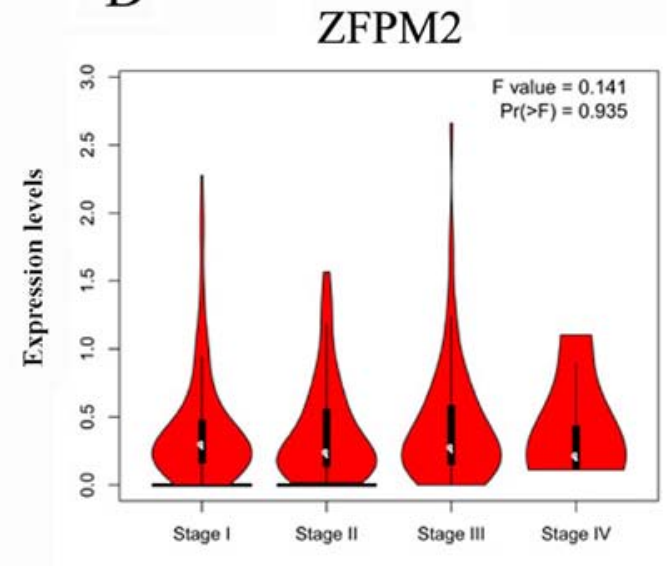

Figure 1. Comparisons of expression levels of lncRNA ZFPM2-AS1 and the ZFPM2 gene. Red represents HCC tissues, grey represents normal liver tissues and black dots represent individual cases. (A) Expression level of lncRNA ZFPM2-AS1 in HCC (369) and normal liver (160) tissues. (B) Expression level of lncRNA ZFPM2-AS1 in tissues of patients with HCC of different clinical stages. (C) Expression level of the ZFPM2 gene in HCC ( $\mathrm{n}=369$ ) and normal liver $(n=160)$ tissues. (D) Expression levels of the ZFPM2 gene in patients with HCC of different clinical stages. lncRNA, long non-coding RNA; AS1, antisense RNA 1; ZFPM2, zinc finger protein, FOG family member 2; HCC, hepatocellular carcinoma; LIHC, liver hepatocellular carcinoma.
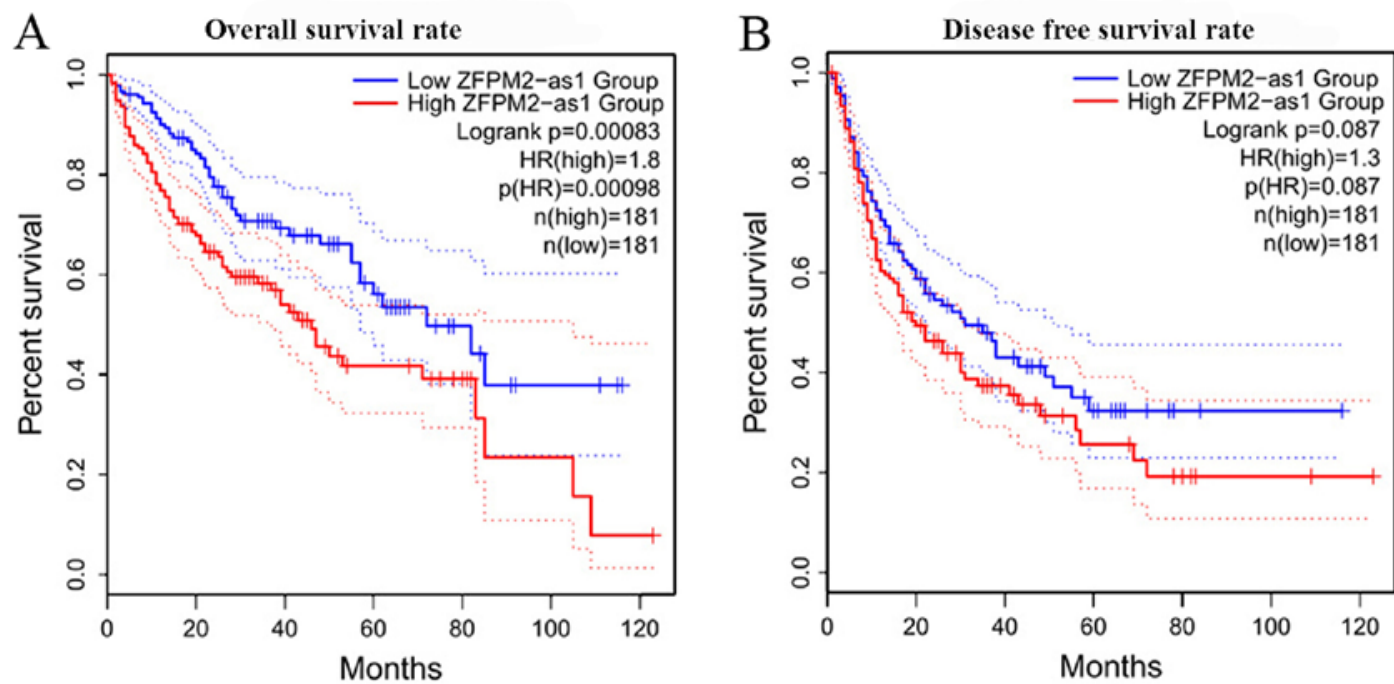

Figure 2. Kaplan-Meier survival curves of patients with HCC based on IncRNA ZFPM2-AS1 expression levels. (A) Overall survival rate of patients with HCC based on IncRNA ZFPM2-AS1 expression levels. (B) Disease-free survival rate of patients with HCC based on lncRNA ZFPM2-AS1 expression levels. lncRNA, long non-coding RNA; AS1, antisense RNA 1; ZFPM2, zinc finger protein, FOG family member 2; HCC, hepatocellular carcinoma; HR, hazard ratio. 
A

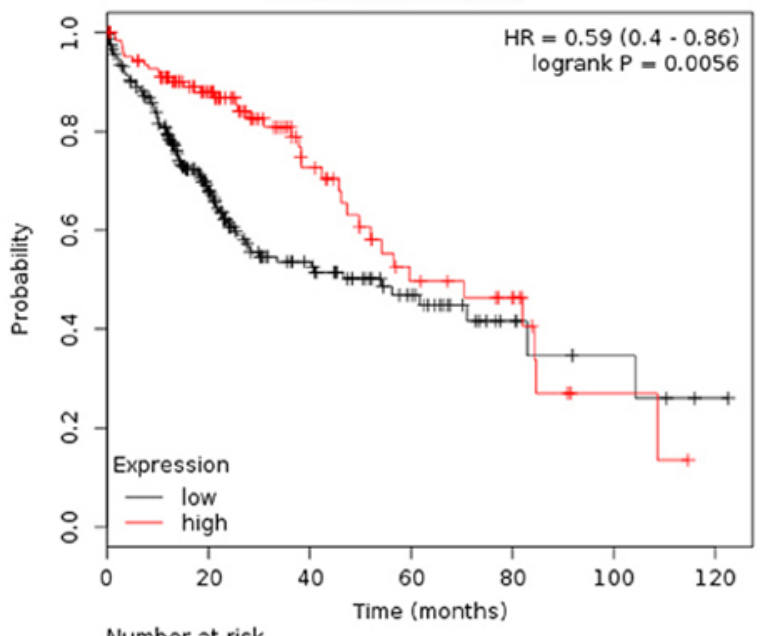

Number at risk

low 238

Overall survival rate
$\mathrm{C}$

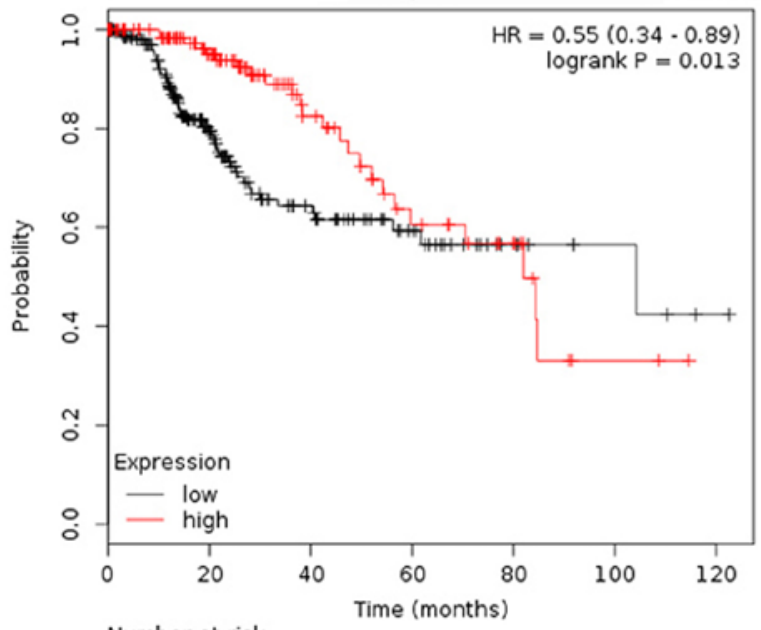

$\mathrm{B}$

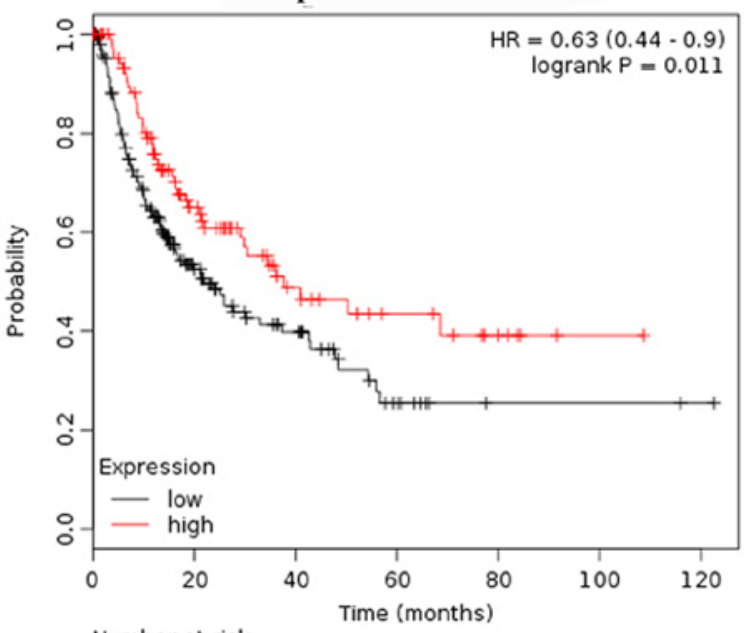

Number at risk

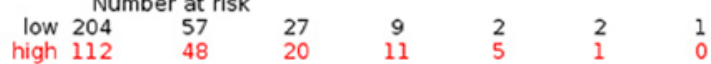

D

Progress free survival rate

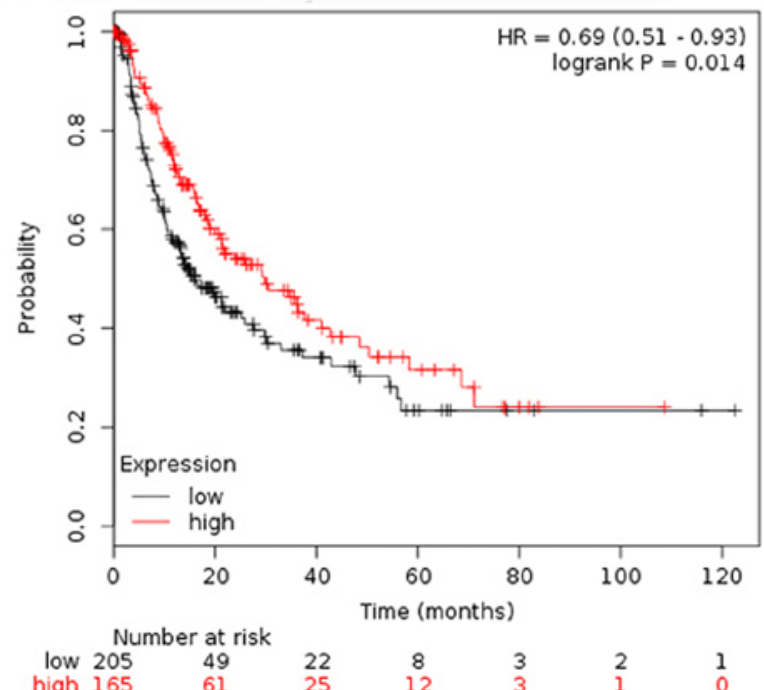

Figure 3. Kaplan-Meier survival curves of patients with HCC based on ZFPM2 gene expression levels. (A) Overall survival rate of patients with HCC based on ZFPM2 gene expression levels. (B) Relapse free survival rate of patients with HCC based on ZFPM2 gene expression levels. (C) Disease specific survival rate of patients with HCC based on ZFPM2 gene expression levels. (D) Progress free survival rate of patients with HCC based on ZFPM2 gene expression levels. lncRNA, long non-coding RNA; AS1, antisense RNA 1; ZFPM2, zinc finger protein, FOG family member 2; HCC, hepatocellular carcinoma; HR, hazard ratio.

A

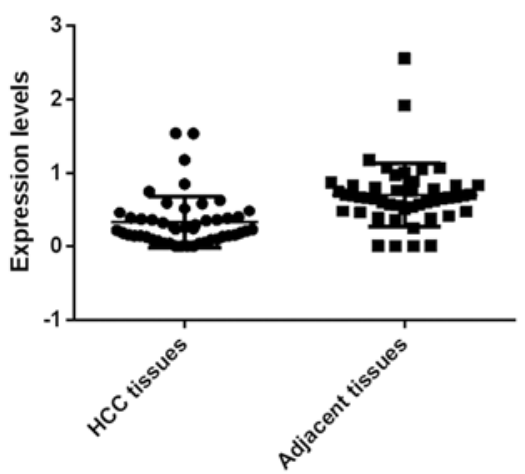

B

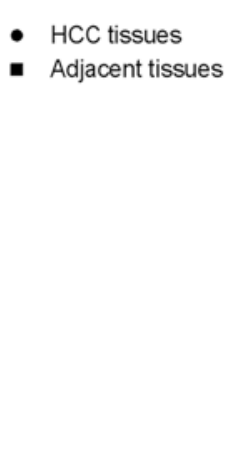

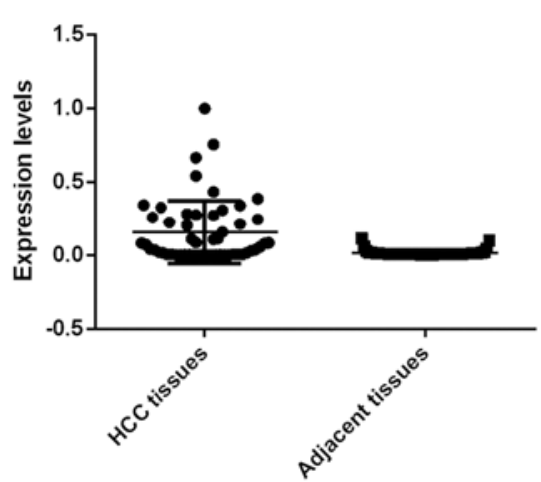

- HCC tissues

- Adjacent tissues

Figure 4. Expression levels of lncRNA ZFPM2-AS1 and the ZFPM2 gene. (A) Expression levels of ZFPM2 in HCC and adjacent tissues. (B) Expression levels of ZFPM2-AS1 in HCC and adjacent tissues. lncRNA, long non-coding RNA; AS1, antisense RNA 1; ZFPM2, zinc finger protein, FOG family member 2; $\mathrm{HCC}$, hepatocellular carcinoma. 


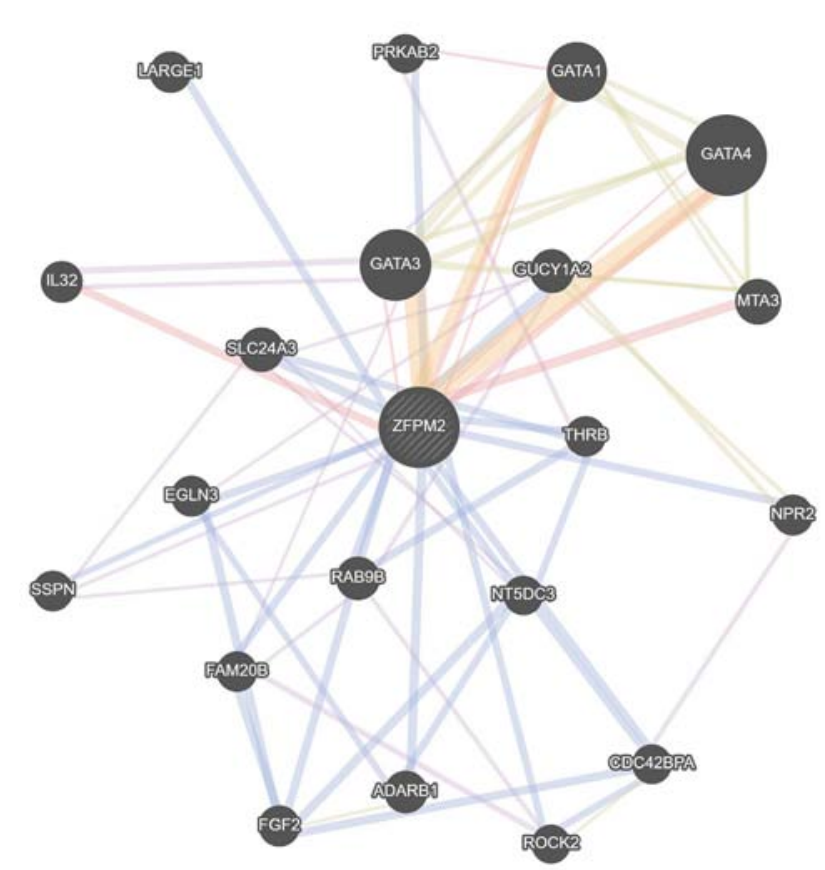

Figure 5. Gene-gene association network of the ZFPM2 gene drawn using GeneMANIA. The circles indicate the function of the gene. ZFPM2, zinc finger protein, FOG family member 2.

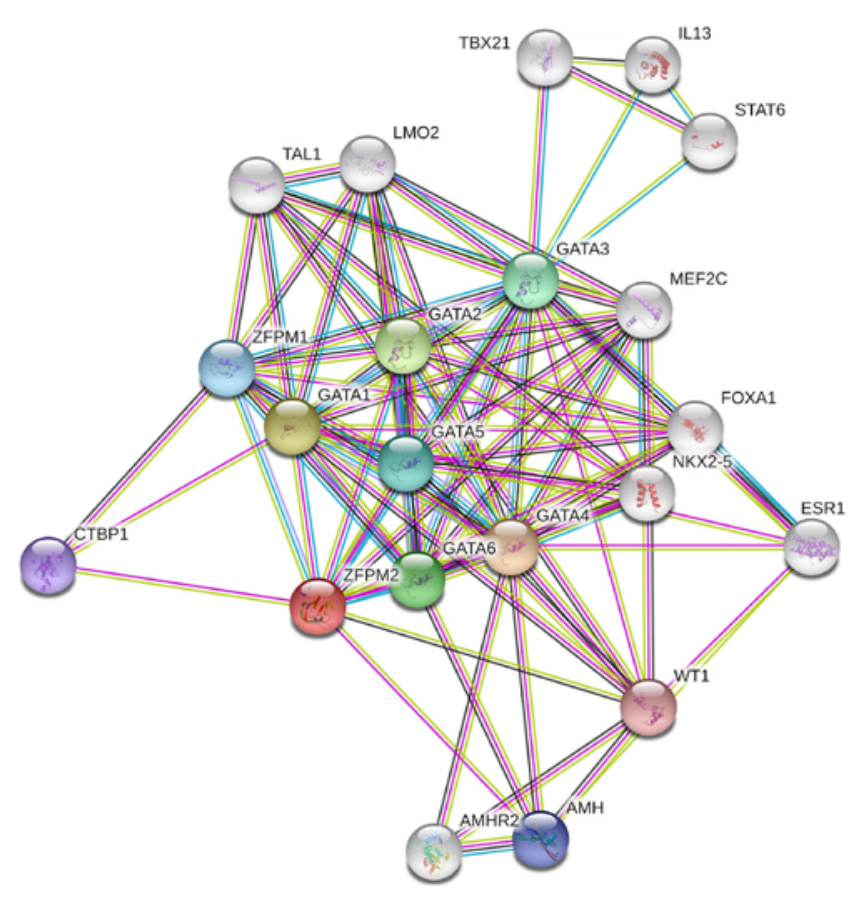

Figure 6. Protein-protein interaction network of the ZFPM2 gene. A network diagram of interactions between proteins associated with the ZFPM2 protein drawn using STRING. ZFPM2, zinc finger protein, FOG family member 2.

KEGG pathway and GO term analyses. The top 200 ZFPM2 and ZFPM2-AS1 associated genes are presented in Table SI, which were identified using the COXPRESdb database. KEGG pathway and GO term analysis of the ZFPM2 associated genes were performed using DAVID. The GO term results demonstrated that these genes may be involved in the 'integral component of plasma membrane', 'protein binding' and 'plasma membrane' (Fig. 8).

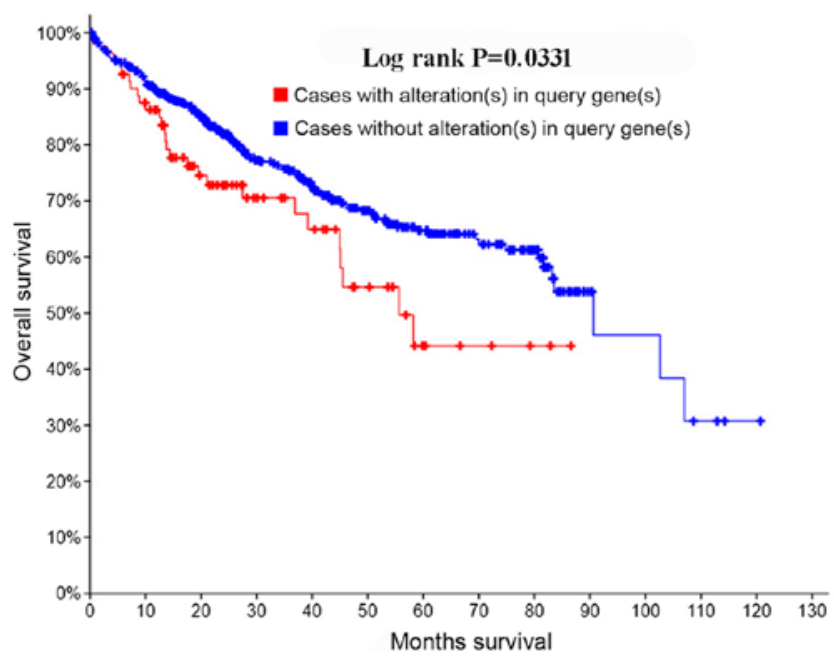

Figure 7. Survival curves for genetic alternations of the zinc finger protein, FOG family member 2 gene.

Validation of the ZFPM2 expression profiling in the GSE14520 dataset. As shown in Fig. 9, the expression levels of the ZFPM2 gene in HCC and non-tumor tissues were consistent in the GSE14520 dataset, in stages I and II. Consistent with TCGA data, ZFPM2 gene expression were significantly decreased in HCC tissues compared with the non-tumor tissues in both stage I and II ( $\mathrm{P}<0.001$; Fig. 9A and C). The ROC analysis of the ZFPM2 gene demonstrated a high accuracy of ZFPM2 in distinguishing between HCC tissues and non-tumor tissues (AUCs, >0.8; Fig. 9B and D)

\section{Discussion}

At present, the etiology of HCC remains poorly understood. In the present study, datasets from the cancer-omics databases TCGA, GTEX and GEO were analyzed in order to confirm the role of lncRNA ZFPM2-AS1 and the ZFPM2 gene in $\mathrm{HCC}$, which are located at the cancer susceptibility locus 8q23 implicated in the carcinogenesis and prognosis of HCC (44). In the present study, it was observed that the expression levels of lncRNA ZFPM2-AS1 and the ZFPM2 gene were significantly different between HCC tissues and normal liver tissues and that these expression levels were also associated with prognosis of HCC. Patients with HCC with ZFPM2 gene alterations had a less favorable prognosis compared with those without ZFPM2 gene alterations. Functional enrichment analysis demonstrated that the ZFPM2 associated genes were primarily involved in the formation of integral component of membrane, protein binding and plasma membrane. To the best of our knowledge, the present study is the first report that aimed to investigate the association between IncRNA ZFPM2-AS1, the ZFPM2 gene and the occurrence and progression of HCC.

Both IncRNA ZFPM2-AS1 and the ZFPM2 gene are located at $8 \mathrm{q} 23$ region, an aggregate of cancer susceptible loci (44-49). Tomlinson et al (48) first identified rs16892766 on chromosome $8 \mathrm{q} 23.3$ as a colorectal cancer susceptibility locus. A previous study identified 41 variants that are associated with venous thromboembolism, and mapped to the ZFPM2-AS1 and ZFPM2 gene region using GWAS 


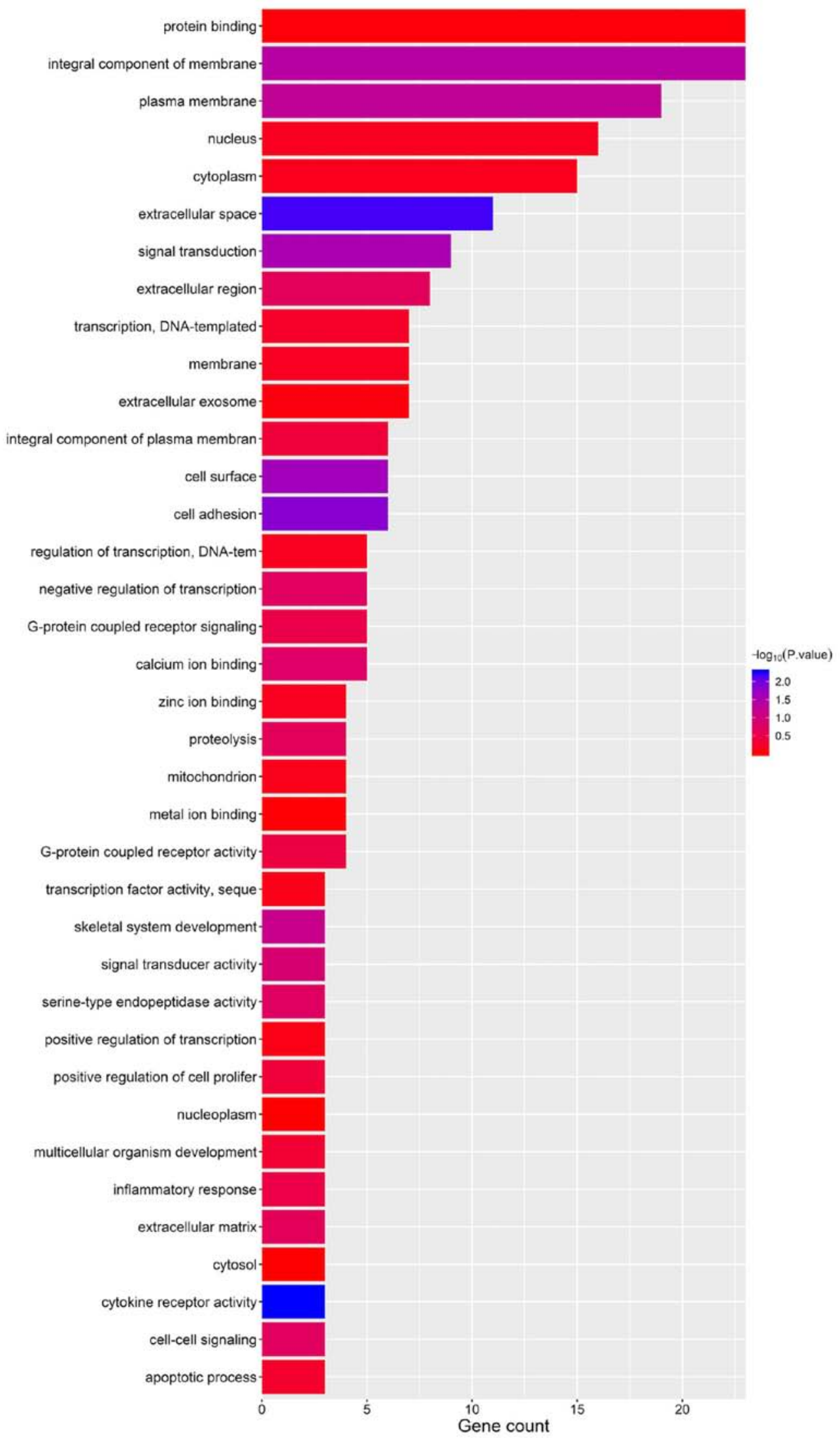

Figure 8. Gene Ontology term enrichment plots of the zinc finger protein, FOG family member 2 associated genes.

catalog (50). In the present study, expression levels of lncRNA ZFPM2-AS1 and the ZFPM2 gene were associated with both the occurrence and prognosis of HCC and mutations of the
ZFPM2 gene were associated with a less favorable prognosis of HCC. These results further confirmed the role of lncRNA ZFPM2-AS1 and the ZFPM2 gene in HCC carcinogenesis. 
A

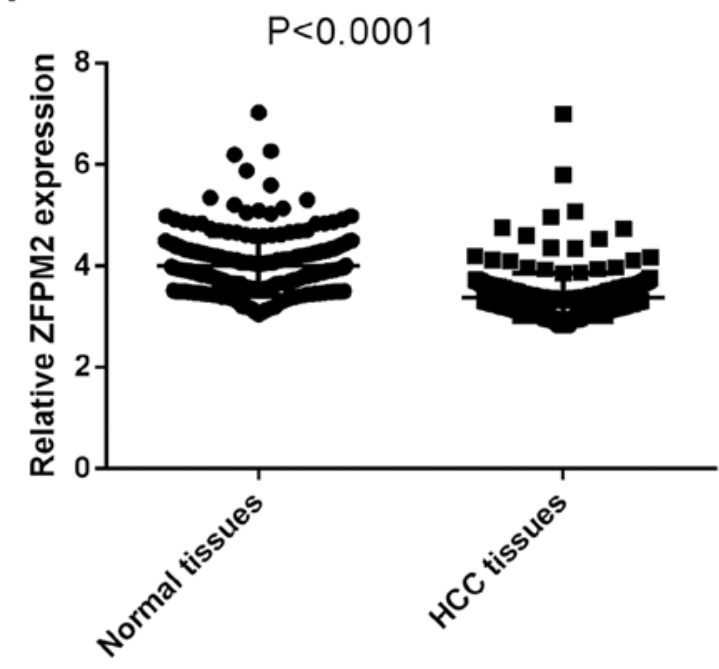

C

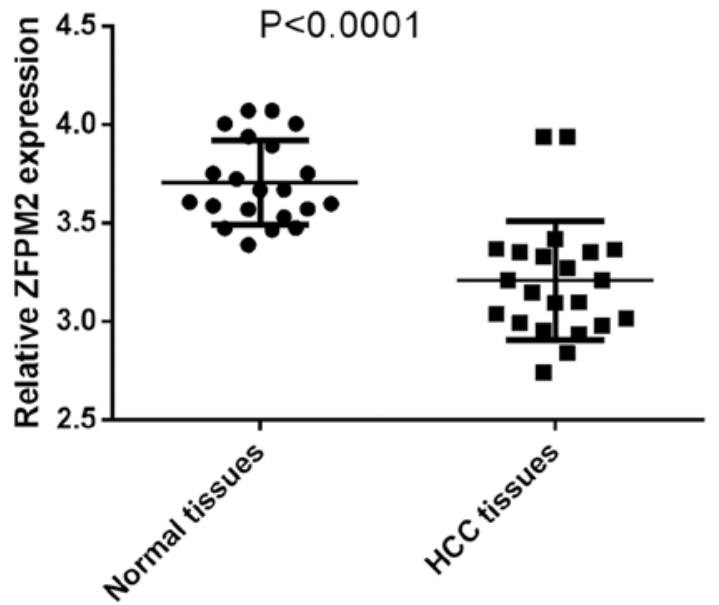

B

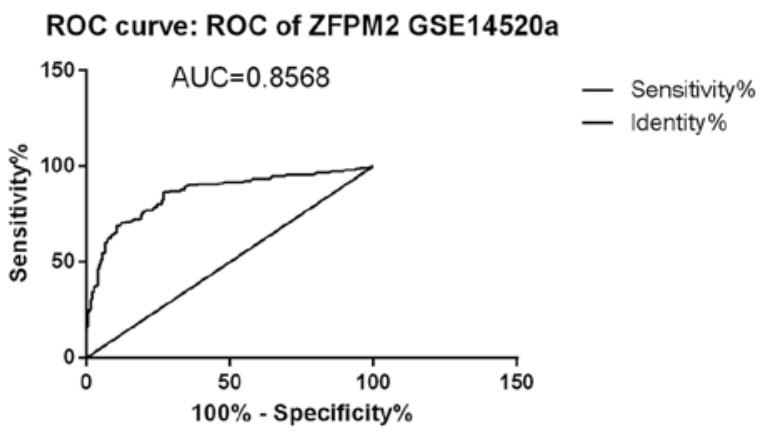

D

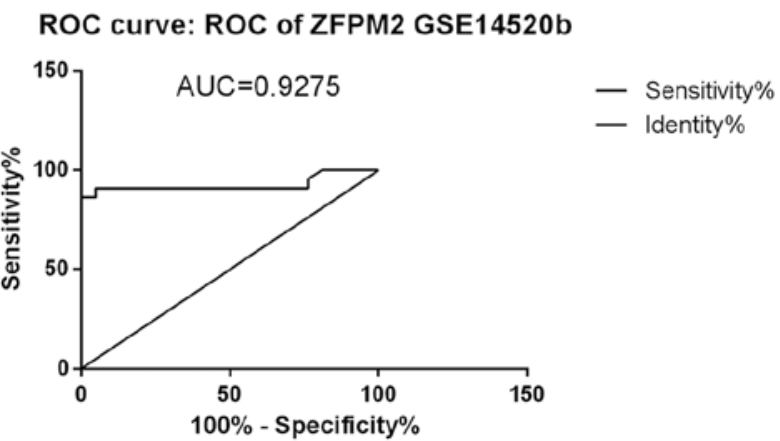

Figure 9. Expression and ROC analysis of ZFPM2 in the GSE14520 dataset of hepatocellular carcinoma and non-tumor tissues. (A) Comparison of ZFPM2 gene expression in tumor and non-tumor tissues in stage I. (B) ROC curve of ZFPM2 between HCC and non-tumor tissues stage I. (C) Comparison of ZFPM2 gene expression in tumor and non-tumor tissues in stage II. (D) ROC curve of ZFPM2 between HCC and non-tumor tissues stage II. ZFPM2, zinc finger protein, FOG family member 2; ROC, receiver operating characteristic; HCC, hepatocellular carcinoma.

In the present study, gene-gene and PPI analyses revealed that ZFPM2-AS1 and ZFPM2 were primarily co-expressed and interacted with the GATA factors, including GATA1, GATA3 and GATA4. The GATA family, which controls the development of diverse tissues by activating or repressing transcription, widely participants in carcinogenesis, differentiation of several types of cancer $(51,52)$. Furthermore, studies have shown that aberrant GATA-3 expression contributes to the occurrence of breast, prostate and pancreatic cancer (53-58). GATA1, GATA4 and GATA6 are also associated with different types of cancer, including colorectal and breast cancer $(59,60)$. The results of the present study demonstrated that ZFPM2 was significantly associated with GATA factors, suggesting its potential role in the development of different types of cancer.

Conclusively, the present study demonstrated that lncRNA ZFPM2-AS1 and the ZFPM2 gene may contribute to the occurrence and progression of HCC. These findings may provide a novel perspective on the underlying molecular mechanisms of HCC and suggest valuable biomarkers and therapeutic targets for patients with HCC. However, further validations with experimental evidence and clinical research are needed to confirm the functions of IncRNA ZFPM2-AS1 and ZFPM2 gene in HCC carcinogenesis.

\section{Acknowledgements}

Not applicable.

\section{Funding}

The present study was funded by the Science Foundation for Outstanding Young People of the Army Military Medical University (Chongqing, China; grant. no. 20170113).

\section{Availability of data and materials}

The datasets used and/or analyzed during the current study are available from the corresponding author on reasonable request. 


\section{Authors' contributions}

XM and YL designed the study. YL, XW, LM, SL, ZM and XF performed the statistical analyses. YL, XW and LM drafted the manuscript. All authors read and approved the final manuscript.

\section{Ethics approval and consent to participate}

The present study was approved by the Ethics Committee of the Army Military Medical University (Chongqing, China) and written informed consent was provided by all participants prior to the study start (approval no. 20170307).

\section{Patient consent for publication}

Not applicable.

\section{Competing interests}

The authors declare that they have no competing interests.

\section{References}

1. Forner A, Gilabert M, Bruix J and Raoul JL: Treatment of intermediate-stage hepatocellular carcinoma. Nat Rev Clin Oncol 11: 525-535, 2014.

2. Zhu RX, Seto WK, Lai CL and Yuen MF: Epidemiology of hepatocellular carcinoma in the Asia-pacific region. Gut Liver 10: 332-339, 2016.

3. GBD 2017 Causes of Death Collaborators: Global, regional, and national age-sex-specific mortality for 282 causes of death in 195 countries and territories, 1980-2017: A systematic analysis for the global burden of disease study 2017. Lancet 392: 1736-1788, 2018.

4. Chen W, Zheng R, Baade PD, Zhang S, Zeng H, Bray F, Jemal A $\mathrm{Yu}$ XQ and He J: Cancer statistics in China, 2015. CA Cancer J Clin 66: 115-132, 2016.

5. Fatica A and Bozzoni I: Long non-coding RNAs: New players in cell differentiation and development. Nat Rev Genet 15: 7-21, 2014

6. Beermann J, Piccoli MT, Viereck J and Thum T: Non-coding RNAs in development and disease: Background, mechanisms, and therapeutic approaches. Physiol Rev 96: 1297-1325, 2016.

7. Schmitt AM and Chang HY: Long noncoding RNAs in cancer pathways. Cancer Cell 29: 452-463, 2016.

8. Mai H, Zhou B, Liu L, Yang F, Conran C, Ji Y, Hou J and Jiang D: Molecular pattern of lncRNAs in hepatocellular carcinoma. J Exp Clin Cancer Res 38: 198, 2019.

9. Yao J, Wu L, Meng X, Yang H, Ni S, Wang Q, Zhou J, Zhang Q, Su K, Shao L, et al: Profiling, clinicopathological correlation and functional validation of specific long non-coding RNAs for hepatocellular carcinoma. Mol Cancer 16: 164, 2017.

10. Yang Y, Chen L, Gu J, Zhang H, Yuan J, Lian Q, Lv G, Wang S, Wu Y, Yang YT, et al: Recurrently deregulated lncRNAs in hepatocellular carcinoma. Nat Commun 8: 14421, 2017.

11. Yu FJ, Zheng JJ, Dong PH and Fan XM: Long non-coding RNAs and hepatocellular carcinoma. Mol Clin Oncol 3: 13-17, 2015.

12. Yang Z, Zhou L, Wu LM, Lai MC, Xie HY, Zhang F and Zheng SS: Overexpression of long non-coding RNA HOTAIR predicts tumor recurrence in hepatocellular carcinoma patients following liver transplantation. Ann Surg Oncol 18: 1243-1250, 2011.

13. Xu S, Kong D, Chen Q, Ping Y and Pang D: Oncogenic long noncoding RNA landscape in breast cancer. Mol Cancer 16: 129, 2017.

14. Liu Y, Pan S, Liu L, Zhai X, Liu J, Wen J, Zhang Y, Chen J, Shen $\mathrm{H}$ and $\mathrm{Hu} \mathrm{Z}$ : A genetic variant in long non-coding RNA HULC contributes to risk of HBV-related hepatocellular carcinoma in a Chinese population. PLoS One 7: e35145, 2012.

15. Lai MC, Yang Z, Zhou L, Zhu QQ, Xie HY, Zhang F, Wu LM, Chen LM and Zheng SS: Long non-coding RNA MALAT-1 overexpression predicts tumor recurrence of hepatocellular carcinoma after liver transplantation. Med Oncol 29: 1810-1816, 2012.
16. Guo S, Chen W, Luo Y, Ren F, Zhong T, Rong M, Dang Y, Feng Z and Chen G: Clinical implication of long non-coding RNA NEAT1 expression in hepatocellular carcinoma patients. Int J Clin Exp Pathol 8: 5395-5402, 2015.

17. Tu ZQ, Li RJ, Mei JZ and Li XH: Down-regulation of long non-coding RNA GAS5 is associated with the prognosis of hepatocellular carcinoma. Int J Clin Exp Pathol 7: 4303-4309, 2014.

18. Yan J, Zhou C, Guo K, Li Q and Wang Z: A novel seven-lncRNA signature for prognosis prediction in hepatocellular carcinoma. J Cell Biochem 120: 213-223, 2019.

19. Kong F, Deng X, Kong X, Du Y, Li L, Zhu H, Wang Y, Xie D, Guha S, Li Z, et al: ZFPM2-AS1, a novel lncRNA, attenuates the p53 pathway and promotes gastric carcinogenesis by stabilizing MIF. Oncogene 37: 5982-5996, 2018.

20. Svensson EC, Tufts RL, Polk CE and Leiden JM: Molecular cloning of FOG-2: A modulator of transcription factor GATA-4 in cardiomyocytes. Proc Natl Acad Sci USA 96: 956-961, 1999.

21. Tevosian SG, Deconinck AE, Tanaka M, Schinke M, Litovsky SH, Izumo S, Fujiwara Y and Orkin SH: FOG-2, a cofactor for GATA transcription factors, is essential for heart morphogenesis and development of coronary vessels from epicardium. Cell 101: 729-739, 2000.

22. Guo L, Wang J, Yang P, Lu Q, Zhang T and Yang Y: MicroRNA200 promotes lung cancer cell growth through FOG2-independent AKT activation. IUBMB Life 67: 720-725, 2015.

23. Aumsuwan P, Khan SI, Khan IA, Ali Z, Avula B, Walker LA, Shariat-Madar Z, Helferich WG, Katzenellenbogen BS and Dasmahapatra AK: The anticancer potential of steroidal saponin, dioscin, isolated from wild yam (Dioscorea villosa) root extract in invasive human breast cancer cell line MDA-MB-231 in vitro. Arch Biochem Biophys 591: 98-110, 2016.

24. Tsang SY, Mei L, Wan W, Li J, Li Y, Zhao C, Ding X, Pun FW, Hu X, Wang J, et al: Glioma association and balancing selection of ZFPM2. PLoS One 10: e0133003, 2015.

25. Hoene V, Fischer M, Ivanova A, Wallach T, Berthold F and Dame C: GATA factors in human neuroblastoma: Distinctive expression patterns in clinical subtypes. Br J Cancer 101: 1481-1489, 2009.

26. Laitinen MP, Anttonen M, Ketola I, Wilson DB, Ritvos O, Butzow R and Heikinheimo M: Transcription factors GATA-4 and GATA- 6 and a GATA family cofactor, FOG-2, are expressed in human ovary and sex cord-derived ovarian tumors. J Clin Endocrinol Metab 85: 3476-3483, 2000.

27. Salonen J, Rajpert-De Meyts E, Mannisto S, Nielsen JE, Graem N, Toppari J and Heikinheimo M: Differential developmental expression of transcription factors GATA-4 and GATA-6, their cofactor FOG-2 and downstream target genes in testicular carcinoma in situ and germ cell tumors. Eur J Endocrinol 162: 625-631, 2010.

28. Karlsson J, Holmquist Mengelbier L, Elfving P and Gisselsson Nord D: High-resolution genomic profiling of an adult Wilms' tumor: Evidence for a pathogenesis distinct from corresponding pediatric tumors. Virchows Archiv 459: 547-553, 2011.

29. Virgone C, Cecchetto G, Ferrari A, Bisogno G, Donofrio V, Boldrini R, Collini P, Dall'Igna P and Alaggio R: GATA-4 and FOG-2 expression in pediatric ovarian sex cord-stromal tumors replicates embryonal gonadal phenotype: Results from the TREP project. PLoS One 7: e45914, 2012.

30. Guan D and Tian H: Integrated network analysis to explore the key genes regulated by parathyroid hormone receptor 1 in osteosarcoma. World J Surg Oncol 15: 177, 2017.

31. Vastrad B, Vastrad C, Godavarthi A and Chandrashekar R: Molecular mechanisms underlying gliomas and glioblastoma pathogenesis revealed by bioinformatics analysis of microarray data. Med Oncol 34: 182, 2017.

32. Li L, Lv L, Liang Y, Shen X, Zhou S, Zhu J and Ma R: Association of 8q23-24 region (8q23.3 loci and 8q24.21 loci) with susceptibility to colorectal cancer: A systematic and updated meta-analysis. Int J Clin Exp Med 8: 21001-21013, 2015.

33. Selenti N, Tzetis M, Braoudaki M, Gianikou K, Kitsiou-Tzeli S and Fryssira H: An interstitial deletion at 8q23.1-q24.12 associated with langer-giedion syndrome/trichorhinophalangeal syndrome (TRPS) type II and Cornelia de Lange syndrome 4. Mol Cytogenet 8: 64, 2015.

34. Plaza-Benhumea L, Valdes-Miranda JM, Toral-Lopez J, PerezCabrera A and Cuevas-Covarrubias S: Trichorhinophalangeal syndrome type II due to a novel 8q23.3-q24.12 deletion associated with imperforate hymen and vaginal stenosis. Br J Dermatol 171: 1581-1583, 2014. 
35. Win AK and Jenkins MA: Is the reported modifying effect of 8q23.3 and 11q23.1 on colorectal cancer risk for MLH1 mutation carriers valid? Int J Cancer 133: 1762-1763, 2013.

36. Pereza N, Severinski S, Ostojic S, Volk M, Maver A, Dekanić KB, Kapović M and Peterlin B: Third case of 8q23.3-q24.13 deletion in a patient with langer-giedion syndrome phenotype without TRPS1 gene deletion. Am J Med Genet A 158A: 659-663, 2012.

37. Carvajal-Carmona LG, Cazier JB, Jones AM, Howarth K, Broderick P, Pittman A, Dobbins S, Tenesa A, Farrington S, Prendergast J, et al: Fine-mapping of colorectal cancer susceptibility loci at 8q23.3,16q22.1 and 19q13.11: Refinement of association signals and use of in silico analysis to suggest functional variation and unexpected candidate target genes. Hum Mol Genet 20: 2879-2888, 2011.

38. Menyhart O, Nagy A and Gyorffy B: Determining consistent prognostic biomarkers of overall survival and vascular invasion in hepatocellular carcinoma. R Soc Open Sci 5: 181006, 2018.

39. Livak KJ and Schmittgen TD: Analysis of relative gene expression data using real-time quantitative PCR and the 2(-Delta Delta C(T)) method. Methods 25: 402-408, 2001.

40. Szklarczyk D, Gable AL, Lyon D, Junge A, Wyder S, Huerta-Cepas J, Simonovic M, Doncheva NT, Morris JH, Bork P, et al: STRING v11: Protein-protein association networks with increased coverage, supporting functional discovery in genome-wide experimental datasets. Nucleic Acids Res 47 (D1): D607-D613, 2019.

41. Roessler S, Jia HL, Budhu A, Forgues M, Ye QH, Lee JS, Thorgeirsson SS, Sun Z, Tang ZY, Qin LX and Wang XW: A unique metastasis gene signature enables prediction of tumor relapse in early-stage hepatocellular carcinoma patients. Cancer Res 70: 10202-10212, 2010.

42. Seimiya M, Ohno S, Yamamoto H, Fujiwara K, Yoshida T, Sawabe Y, Sogawa K, Matsushita K, Yokosuka O and Nomura F: Child-Pugh score is altered by the albumin measurement method. Hepatology 57: 2093-2094, 2013.

43. Taniai M, Tomimatsu M, Okuda H, Saito A and Obata H: Immunohistochemical detection of proliferating cell nuclear antigen in hepatocellular carcinoma: Relationship to histological grade. J Gastroenterol Hepatol 8: 420-425, 1993.

44. Ghorbanoghli Z, Nieuwenhuis MH, Houwing-Duistermaat JJ, Jagmohan-Changur S, Hes FJ, Tops CM, Wagner A, Aalfs CM, Verhoef S, Gómez García EB, et al: Colorectal cancer risk variants at $8 \mathrm{q} 23.3$ and $11 \mathrm{q} 23.1$ are associated with disease phenotype in APC mutation carriers. Fam Cancer 15: 563-570, 2016.

45. Li M and Gu Y: Quantitative assessment of the influence of common variation rs16892766 at 8q23.3 with colorectal adenoma and cancer susceptibility. Mol Genet Genomics 290: 461-469, 2015

46. Talseth-Palmer BA, Wijnen JT, Brenne IS, Jagmohan-Changur S, Barker D, Ashton KA, Tops CM, Evans TJ, McPhillips M, Groombridge $\mathrm{C}$, et al: Combined analysis of three Lynch syndrome cohorts confirms the modifying effects of 8q23.3 and 11q23.1 in MLH1 mutation carriers. Int J Cancer 132: 1556-1564, 2013.

47. Wijnen JT, Brohet RM, van Eijk R, Jagmohan-Changur S, Middeldorp A, Tops CM, van Puijenbroek M, Ausems MG, Gómez García E, Hes FJ, et al: Chromosome 8q23.3 and 11q23.1 variants modify colorectal cancer risk in Lynch syndrome. Gastroenterology 136: 131-137, 2009.
48. Tomlinson IP, Webb E, Carvajal-Carmona L, Broderick P, Howarth K, Pittman AM, Spain S, Lubbe S, Walther A, Sullivan K, et al: A genome-wide association study identifies colorectal cancer susceptibility loci on chromosomes 10p14 and 8q23.3. Nat Genet 40: 623-630, 2008.

49. Okamoto H, Yasui K, Zhao C, Arii S and Inazawa J: PTK2 and EIF3S3 genes may be amplification targets at 8q23-q24 and are associated with large hepatocellular carcinomas. Hepatology 38 : 1242-1249, 2003.

50. Welter D, MacArthur J, Morales J, Burdett T, Hall P, Junkins H, Klemm A, Flicek P, Manolio T, Hindorff L and Parkinson H: The NHGRI GWAS catalog, a curated resource of SNP-trait associations. Nucleic Acids Res 42 (Database Issue): D1001-D1006, 2014.

51. Zheng R and Blobel GA: GATA transcription factors and cancer. Genes Cancer 1: 1178-1188, 2010.

52. Chou J, Provot S and Werb Z: GATA3 in development and cancer differentiation: Cells GATA have it! J Cell Physiol 222: 42-49, 2010.

53. Albergaria A, Paredes J, Sousa B, Milanezi F, Carneiro V, Bastos J, Costa S, Vieira D, Lopes N, Lam EW, et al: Expression of FOXA1 and GATA-3 in breast cancer: The prognostic significance in hormone receptor-negative tumours. Breast Cancer Res 11: R40, 2009.

54. Voduc D, Cheang M and Nielsen T: GATA-3 expression in breast cancer has a strong association with estrogen receptor but lacks independent prognostic value. Cancer Epidemiol Biomarkers Prev 17: 365-373, 2008.

55. Kouros-Mehr H, Bechis SK, Slorach EM, Littlepage LE, Egeblad M, Ewald AJ, Pai SY, Ho IC and Werb Z: GATA-3 links tumor differentiation and dissemination in a luminal breast cancer model. Cancer Cell 13: 141-152, 2008.

56. Eeckhoute J, Keeton EK, Lupien M, Krum SA, Carroll JS and Brown M: Positive cross-regulatory loop ties GATA-3 to estrogen receptor alpha expression in breast cancer. Cancer Res 67: 6477-6483, 2007.

57. Gulbinas A, Berberat PO, Dambrauskas Z, Giese T, Giese N, Autschbach F, Kleeff J, Meuer S, Büchler MW and Friess H: Aberrant gata-3 expression in human pancreatic cancer. J Histochem Cytochem 54: 161-169, 2006.

58. Parikh P, Palazzo JP, Rose LJ, Daskalakis C and Weigel RJ: GATA-3 expression as a predictor of hormone response in breast cancer. J Am Coll Surg 200: 705-710, 2005.

59. Gong X, Liu W, Wu L, Ma Z, Wang Y, Yu S, Zhang J, Xie H, Wei G, Ma F, et al: Transcriptional repressor GATA binding 1-mediated repression of SRY-box 2 expression suppresses cancer stem cell functions and tumor initiation. J Biol Chem 293: 18646-18654, 2018.

60. Xu K, Wang J, Gao J, Di J, Jiang B, Chen L, Wang Z, Wang A, $\mathrm{Wu} \mathrm{F}, \mathrm{Wu} \mathrm{W}$, et al: GATA binding protein 2 overexpression is associated with poor prognosis in KRAS mutant colorectal cancer. Oncol Rep 36: 1672-1678, 2016.

(i) $($ This work is licensed under a Creative Commons Attribution-NonCommercial-NoDerivatives 4.0 International (CC BY-NC-ND 4.0) License. 